\title{
Students' Immersive Experience in Initial Teacher Training in a Virtual World to Promote Sustainable Education: Interactivity, Presence, and Flow
}

\author{
María Graciela Badilla-Quintana ${ }^{1, *(1)}$ and Francisco Javier Sandoval-Henríquez ${ }^{2}$ \\ 1 Centro de Investigación en Educación y Desarrollo CIEDE-UCSC, Departamento de Currículum y Evaluación, \\ Facultad de Educación, Universidad Católica de la Santísima Concepción, Concepción 4090541, Chile \\ 2 Unidad de Autoevaluación, Dirección de Gestión Estratégica, Universidad Católica de la Santísima \\ Concepción, Concepción 4090541, Chile; fjsandoval@ucsc.cl \\ * Correspondence: mgbadilla@ucsc.cl
}

check for

updates

Citation: Badilla-Quintana, M.G.; Sandoval-Henríquez, F.J. Students' Immersive Experience in Initial

Teacher Training in a Virtual World to Promote Sustainable Education: Interactivity, Presence, and Flow. Sustainability 2021, 13, 12780. https://doi.org/10.3390/su132212780

Academic Editors: Gwo-Jen Hwang, Haoran Xie and Xiao-Fan Lin

Received: 15 October 2021

Accepted: 11 November 2021

Published: 19 November 2021

Publisher's Note: MDPI stays neutral with regard to jurisdictional claims in published maps and institutional affiliations.

Copyright: (c) 2021 by the authors. Licensee MDPI, Basel, Switzerland. This article is an open access article distributed under the terms and conditions of the Creative Commons Attribution (CC BY) license (https:/ / creativecommons.org/licenses/by/ $4.0 /)$.

\begin{abstract}
The Virtual World is a technology that has created countless opportunities for teaching and learning, innovating traditional and online education, and promoting a more sustainable and accessible education. Through their avatars and digital representations, students can navigate, observe, and manipulate virtual objects, while interacting with their classmates inside the simulated 3D environment. This study examined how preservice teachers experience and participate in a VW that simulates a university campus, considering three main components: interactivity, sense of presence, and state of flow. A total of 103 pedagogy students, enrolled in an educational technology course, participated in the study. A postintervention survey was implemented, as well as a self-report about the immersive experience. The results show a high level of agreement with the survey's affirmations, which allows for the determination of the favorable levels of interactivity, presence, and flow, as well as the meaningful and positive associations among these technological properties. Guidelines are argued to deepen the Virtual World's potential and are given for the design of pedagogical activities in those environments.
\end{abstract}

Keywords: experiential learning; virtual world; higher education; preservice teachers

\section{Highlights}

- Immersive reality can be useful for practicing teaching in initial teacher training

- $3 \mathrm{D}$ environments may promote disciplinary and pedagogical practicing

- Immersive worlds enable sustainable education-simulating practice centers

- Immersive technology enables preservice students to be educated to be better teachers in the near future

\section{Introduction}

Because of the sanitary crisis caused by COVID-19, it is highly possible that teaching and learning methods have been permanently modified. This emergency massively shut down all in-person educational activities throughout 2020, leading to the widespread use of distance modalities through the incorporation of technologies for the support and wellbeing of educational communities [1].

In the near future, research on COVID-19 in the field of education is likely to be oriented towards the application of effective pedagogical methods for training students at different educational stages [2].

One technology that has projected opportunities for learning and innovation in education, even before the pandemic, is the Virtual World (VW). A broad range of universities and educational organizations have incorporated this virtual community into their educational pathways to support class attendance, knowledge transference, and cognitive skills development [3-7], especially considering that they also provide a space for practicing 
collaborative learning, allowing students to develop other skills, such as group work, critical thinking, reflection, and participatory learning. The UNESCO [1] affirms that all these skills must be considered for a sustainable education because they promote students' autonomy in shaping a sustainable and just future.

The VW has been mainly used for virtual conferences, field trips, and simulations. Students attend the virtual environment using their avatars and communicate with their instructor and other students through voice and chat. For example, Winkelmann et al. implemented a virtual lab for teaching chemistry to university students in the United Stated [8]. Participants reported a favorable opinion of the VW experience and indicated that the environment minimized distractions and facilitated certain experimental procedures. Seifan et al. also developed a virtual laboratory in which students from New Zealand, enrolled in a biotechnology course, participated [6]. The undergraduates gained a thorough understanding of fermentation principles, laboratory safety rules, experiment design, and data analysis. Consequently, the authors infer that the VW allows them to perform hands-on experiments effectively. Recently, the Australian authors, Ghanbarzadeh and Ghapanchi, designed a VW that simulated a university campus with computer labs, as well as discussion and lecture rooms [3]. Students were able to navigate and manipulate objects within the environment, and they reported a high level of satisfaction and acceptance of the technology. Consequently, the authors argue that undergraduates are more likely to participate in courses offered in VW-based learning environments.

In this context, we can affirm that a VW is a shared environment, simulated, and that it fits into the framework of a physical world. Nevertheless, the difference between the two worlds lies in the types of experience offered by the VW's blend of technical features. Girvan identifies six features: (i) The avatar, which provides the user with an active agent to mediate interactions with others; (ii) Multiple users, who support a sense of presence within the shared space; (iii) Communication tools, which enable the interaction between users through text- and voice-based media, and allow for the inclusion of images, symbols, and videos; (iv) Content creation tools, which allow for the uploading of content created in external software, or for generating content while remaining in the VW; (v) Persistence, which preserves the location of the avatar and its created objects; and (vi) Space representation, which provides a graphical representation of the space and shows each action performed by an avatar within the VW [9].

The technical features of this environment have an impact on the users' immersive experiences. With regard to this, the literature has identified three aspects of experience that are required components of a VW: interactivity, sense of presence, and flow state.

These three dimensions of experience are rarely addressed by the empirical studies. First, most research has examined the effect of VW integration on variables, such as academic engagement, academic outcomes, and cognitive skills $[3,6,7,10,11]$. While the effectiveness of using this medium as an educational tool is discussed, less research focuses on how students learn in this environment and, specifically, how certain components of the VW relate to effective learning.

Second, research has been focused on exploring the advantages and disadvantages of VW as a resource for teaching and learning from the perception of teachers and students [12-15]. While perception and adoption are frequently studied whenever a new technology emerges, VW possesses distinct features from other technological media, which have not received sufficient consideration by researchers.

Thorne and Macgregor argue that higher education institutions have an important contribution to make to sustainable education [16]. Through VW, they encouraged Australian students to engage with sustainability curricula. The findings confirmed high levels of participation in the VW, which increased critical thinking and problem-solving for sustainable learning in the real world.

The systematic review by Abad-Segura et al. highlights the sustainability of immersive technologies in higher education, as they favor more motivating and interactive activities, promoting a more sustainable, equitable, and egalitarian education. This benefits 
students' cognitive, inclusive, and emotional processes, as a sustainable tool in line with the Sustainable Development Goals, adopted by the United Nations [17].

Given the rising popularity and the scarce empirical studies on the integration of the VW into educational processes, this inquiry is focused on determining how students in initial teacher training (ITT) experience their participation in a VW in terms of three components: interactivity, sense of presence, and flow state.

\section{Theoretical Background}

\subsection{Components of the Virtual World Experience}

Educational neuroscience experts argue that this technology is promising because of its capacity to create three-dimensional scenes that produce vivid and emotional experiences for students [18]. The components of the immersive experience in a VW are described below.

First, interactivity is a subjective, engaging, and spontaneous feeling provoked by technology [19]. It is defined as the degree to which a user can partake in modifying the form and content of a virtual environment or object [20]. Complementarily, Lee and Kim conceptualize it as the two-way human-machine interaction, which is highly dependent on the presented content and the technology's performance [21]. According to Gómez, highly interactive virtual environments are attractive for incorporation into the classroom, as they motivate students and facilitate tasks that lead to a better representation of spatial knowledge [18].

Second, the sense of presence consists of the illusion of being at a certain place, despite knowing that one is not there. It happens as users explore the boundaries of an immersive system, i.e., the more they investigate, the greater the likelihood of presence breaks [22]. In Girvan's words, the sense of presence would suggest that the user feels represented in the space and that others acknowledge that representation [9]. Furthermore, they also are aware that others know of their arrival, departure, and any of their actions while in the VW. This cognitive response allows for authentic experiences within the virtual environment, which, in turn, meets the characteristics of the physical world in terms of visual fidelity, laws of physics, and social interactions, where the learner can experiment and explore learning freely [23].

Third, the state of flow relates to a psychological experience in which a subject becomes involved or absorbed in a given activity, such that he or she becomes fascinated by it, paying full attention, and suppressing extraneous thoughts. In addition, the user perceives that the activity is achievable and thinks that they are competent to carry it out [24]. SandovalHenríquez and Badilla-Quintana argue that, by developing activities with immersive technology, students achieve better focus and undergo less stress as they enjoy them [25].

\subsection{Experiential Learning Theory}

The inclusion of the VW in the educational environment allows for the involvement of the Experiential Learning Theory by substituting real contexts that are not possible to use because of time or space constraints, or that are not safe for a learner to approach.

Experiential learning is also understood as "the process whereby knowledge is created through the transformation of experience. Knowledge results from a combination of a grasping and transforming experience" [26]. This theory is built on six propositions: (i) Learning is a process and not an outcome; (ii) Learners' beliefs about a subject are being challenged and verified by new ideas and knowledge; (iii) Learning is driven by disagreements and differences. Resolving these conflicts generates new learning; (iv) Learning involves adapting to a given context; (v) Learning results from assimilating new experiences and existing concepts, and (vi) Learners create new knowledge, skills, and attitudes [27]. On the basis of these principles, Kolb holds that students must confront four modes of experiential learning: (i) Concrete experiences, where they engage in a new situation with an open mind and without prejudice; (ii) Reflective observation, where they reflect on and observe those experiences from different perspectives; (iii) Abstract 
conceptualization, where they can transform their observations by creating concepts that are generalizations or logical principles; and, (iv) Active experimentation, where they use their developed theories to solve a given challenge or problem [26].

This theory is useful for putting what students have learned into practice in complex situations so that, after actively experiencing their new learning, the process is restarted [28]. In this sense, VW fosters the student's active participation under the Learning by Doing methodology proposed by Dewey and empowers them to apply knowledge and skills in a multiplicity of situations, both inside and outside the classroom [29].

\section{Research Questions and Hypothesis}

In this context, the research questions $(\mathrm{RQ})$ and respective hypotheses $(\mathrm{H})$ are presented. In addition, theoretical and empirical support is provided to back up the hypotheses.

Q1: How do preservice teachers experience their involvement in a Virtual World?

Hypothesis 1 (H1). Students report a favorable degree of agreement with the immersive experience.

This hypothesis is backed by previous empirical studies. In the work of Ghanbarzadeh and Ghapanchi, participants reported a high degree of satisfaction with the educational experience in a VW [3]. In Lorenzo-Alvarez et al., research participants gave a high rating to the virtual environment. Therefore, the authors argue that the VW is an effective and well-accepted medium for teaching content to undergraduates [11].

Q2: What is the correlation between the components of experience, interactivity, sense of presence, and flow state?

Hypothesis 2 (H2). Interactivity is positively related to a sense of presence.

This hypothesis is supported by Kwon's study, which indicates that interactivity leads to an improved sense of presence. This, in turn, helps the user to recognize the more real and direct immersive experience [27]. There is a broad consensus in the literature that interacting with a virtual environment, rather than just observing it, leads to a greater presence in it $[19,23]$.

Hypothesis 3 (H3). Interactivity is positively related to the flow state.

This hypothesis is supported by previous work verifying the positive relationship between both concepts. From the findings, the faster the user-technology interaction, the stronger the flow experience, where events occurring in the surrounding physical environment are excluded [21,30,31].

Hypothesis 4 (H4). Sense of presence is positively related to flow state.

This hypothesis is supported by previous studies, evidencing a positive and significant correlation, highlighting that presence allows users to immerse themselves in realistic experiences, leading to high concentration and connection with the activity $[23,32]$.

Q3: Are there gender differences in the components of the immersive experience?

Hypothesis 5 (H5). There are gender differences in interactivity components, sense of presence, and flow state in favor of men.

While the current findings do not clearly indicate whether a gender-based advantage is gained in the VW, studies in the ICT domain have indicated that men more frequently use computers and videogames at home, and even develop higher Internet addiction [28,33]. From the above, it is inferred that inexperience with videogames may place the traditional college-aged female population at particular risk of being at a disadvantage in a Virtual World learning context. 


\section{Method}

\subsection{Research Design}

The research has a quantitative method and a pre-experimental design with a single group. In the experiment, the use of an immersive VW was applied to university students, and then the dependent variables, interactivity, presence, and flow were measured. Moreover, this is a descriptive, correlational, and transactional study, given that it attempts to crystallize the data gathered at a single time [34].

\subsection{Participants}

The sample was formed by 103 students belonging to four higher education institutions: two located in Chile $(n=91 ; 88.3 \%)$, one located in Brazil $(n=6 ; 5.8 \%)$, and one in Honduras $(n=6 ; 5.8 \%)$. Participants were selected among students enrolled in the educational technology course as part of a pedagogy program at their institutions. It is worth noting that the Brazilian participants were fluent in both reading and writing Spanish, so they interacted normally with the rest of the native Spanish-speaking participants. Table 1 shows the sample's characteristics.

Table 1. Participant characteristics.

\begin{tabular}{lcc}
\hline Sociodemographic Variables & $n$ & $\%$ \\
\hline Gender & & $79 \%$ \\
Female & 81 & $21 \%$ \\
Male & 22 & $15 \%$ \\
Field of study & 15 & $18 \%$ \\
Language and communication education & 19 & $44 \%$ \\
Mathematics education & 45 & $6 \%$ \\
Elementary education & 6 & $6 \%$ \\
English as a second language & 6 & $7 \%$ \\
Special education & 7 & $3 \%$ \\
Kindergarten education & 3 & $1 \%$ \\
Physical education & 1 & $1 \%$ \\
Music education & 1 & \\
Chemistry education & & $18 \%$ \\
Year & 18 & $18 \%$ \\
First year & 18 & $4 \%$ \\
Second year & 4 & $43 \%$ \\
Third year & 44 & $18 \%$ \\
Fourth year & 19 & \\
Fifth year & & \\
\hline
\end{tabular}

(Source: authors' own creation).

With regard to ethical considerations, the students voluntarily expressed their intention to participate in the study through a consent form. This document informed them that the sessions would be recorded and that only the researchers would have access to the data analysis. All the information was used confidentially, safeguarding the students identities. This study was approved by the Ethics, Bioethics, and Biosafety Committee at the institution, to which the researchers belong. This committee granted the authorization considering the researchers' professionalism, the information's confidentiality, and the safekeeping of the data. In addition, the committee annually monitors compliance with the ethical regulations of the project.

\subsection{Virtual World}

The VW was developed through a 3D open-source app server called OpenSim. An engineering team designed a $65.536 \mathrm{~m}^{2}$ university campus, with classrooms, labs, auditoriums, green areas equipped with chairs, tables, computers, and media panels, with forward and backward navigation buttons for displaying PowerPoint presentations, saved as .jpeg 
images. They also allowed access to webpages and video playback. Figure 1 shows the Virtual World, called "Tymmi", that simulates the university campus.
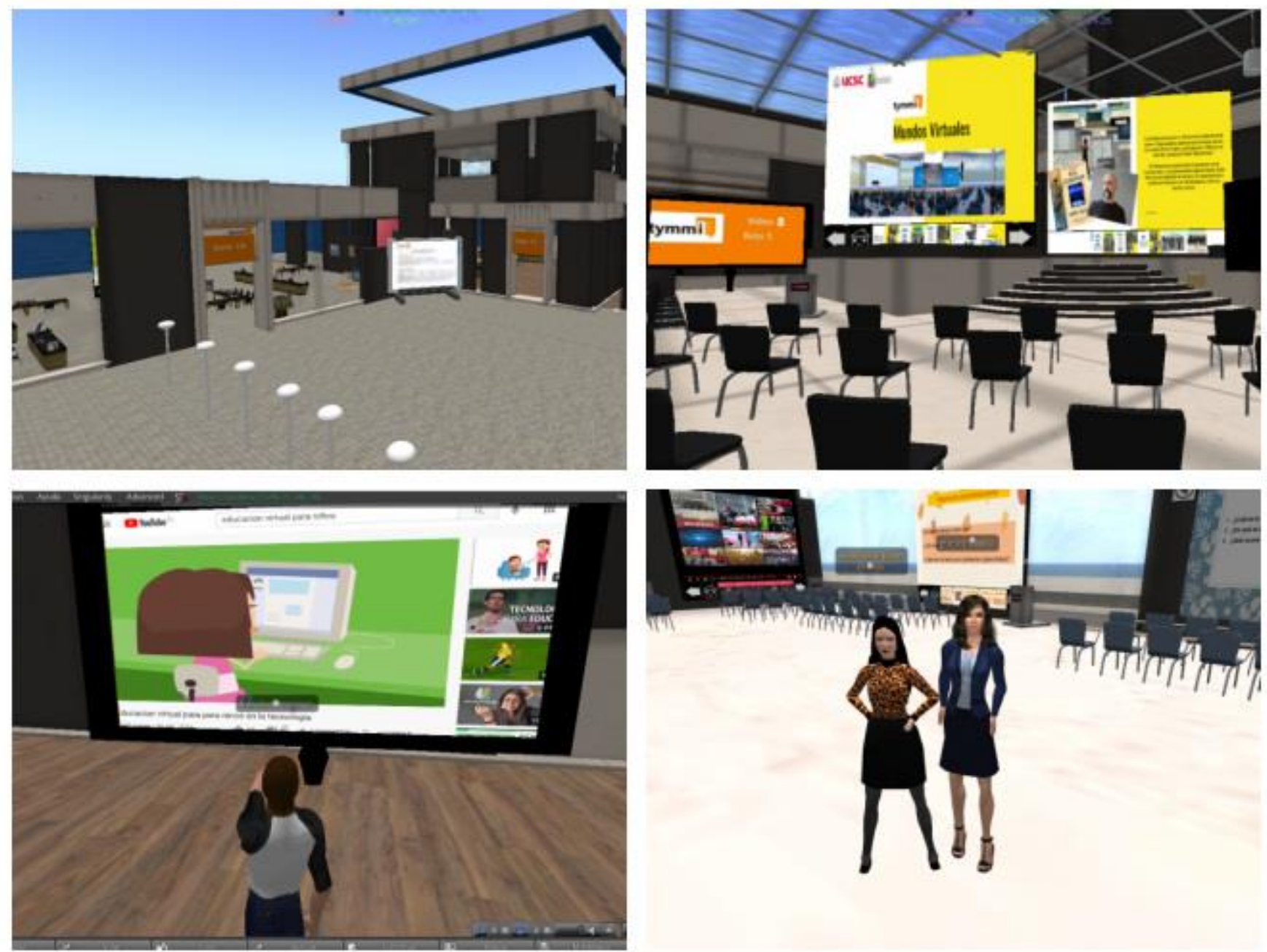

Figure 1. Upper: VW Tymmi's building (left), and an auditorium (right). Lower: an avatar searching for videos in a multimedia panel linked to YouTube (left), and a scene with avatars looking the camera (right). (Source: authors' own creation).

\subsection{Educational Intervention}

An educational intervention was designed according to the principles of the Experiential Learning Theory. Its main purpose was to strengthen initial teacher training (ITT) and the students' pedagogical and technological skills through the educational advantages of VW. The intervention consisted of six 90-min sessions over a period of two months.

Each session was led by a moderator from the research team, who sent instructions regarding the activities to be developed in the following session. For instance: You have started a didactic unit and you need to know your students' preconceptions of the content, identify possible obstacles, avoid a diversified process and make decisions about the development of the unit. As a pedagogical decision, you use a strategy to explore your students' prior knowledge.

Additionally, the moderator sent pedagogical material to the participants to support them in the planning of their class proposal, such as tutorial videos, lesson plans, and supplementary reading texts, among others.

Participants were invited to plan and execute an educational activity for a course and learning objective of their choice. The execution of each session was based on the roleplaying technique. Participants were invited to adopt two roles: (a) Teacher, when executing the educational activity, and (b) Student, when participating in the activities proposed by their 
peers. In the teaching processes, participants were motivated to ask questions and to adopt behaviors according to the educational level indicated. The moderator's role was to listen attentively to the presentations and offer adequate feedback through simulated gestures, clapping, laughing, or using emoticons (experiential learning mode: concrete experience). At the end of the session, the moderator could reflect upon the fulfillment of the situation presented, as well as the performance of each presentation. Participants reflected on the experience, about the different strategies used by their peers to approach the situation, the resources available for teaching, and their strengths, as well as aspects to improve in their roles as teachers (experiential learning mode: reflective observation).

Students received continuous written feedback on their strengths and areas for development in terms of individual performance and the pedagogical skills worked on. Readings and/or technological resources were also suggested for improving those aspects (experiential learning mode: abstract conceptualization).

In the following sessions, facing new situations, students were expected to be able to develop the proposed challenges with greater mastery (experiential learning mode: active experimentation).

The following is a brief description of the sessions that comprised the educational intervention. The objectives of the first session were to welcome participants to the VW, called "Tymmi", and focus on the participants' training in the development of the basic skills needed for interaction with the immersive virtual environment, including (a) Movement skills, such as walking, running, flying, teleportation, and sitting; (b) Impersonation skills, such as designing costumes and changing appearance; (c) Communication skills, such as receiving and sending voice and text chat; and, (d) Camera control skills, including correctly following the slides of a presentation, and displaying activities to another VW or Internet site. Moreover, instructions were given on the work modality, specifically, the roleplaying technique.

In Sessions Two through Six, each participant executed their educational activity in approximately $7 \mathrm{~min}$. Each session pursued a specific purpose. In the second session, participants were invited to propose a strategy to inquire about their students' prior knowledge of a learning objective. In the third session, they had to teach how to construct a graphic organizer to synthesize content. In the fourth session, they had to apply a classroom assessment technique and provide feedback on their students' responses. In the fifth session, they were asked to present the characteristics of the institutional educational project of the fictional school where they would be working. Finally, in the sixth session, the objective was to apply a curricular adaptation of access, referring to the organization of time, organization of the environment, presentation of information, and forms of response. Figure 2 shows some scenes from the participants' educational activities.
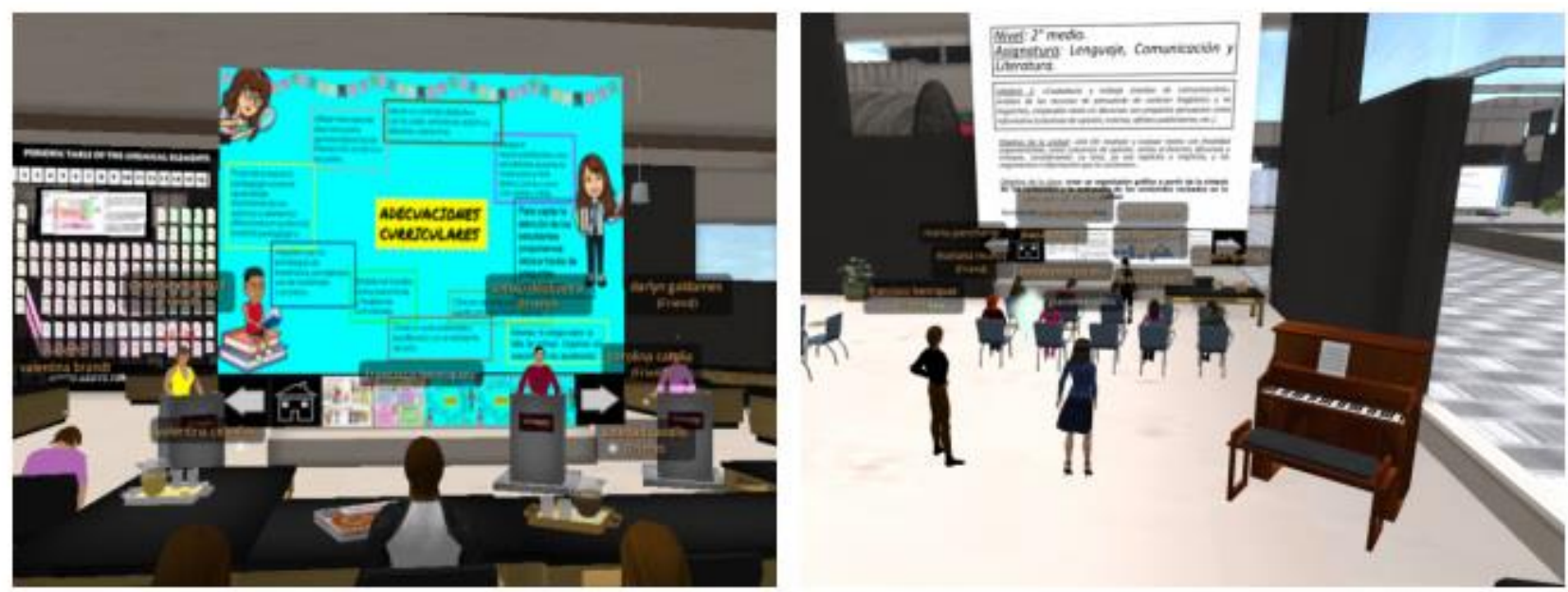

Figure 2. Cont. 

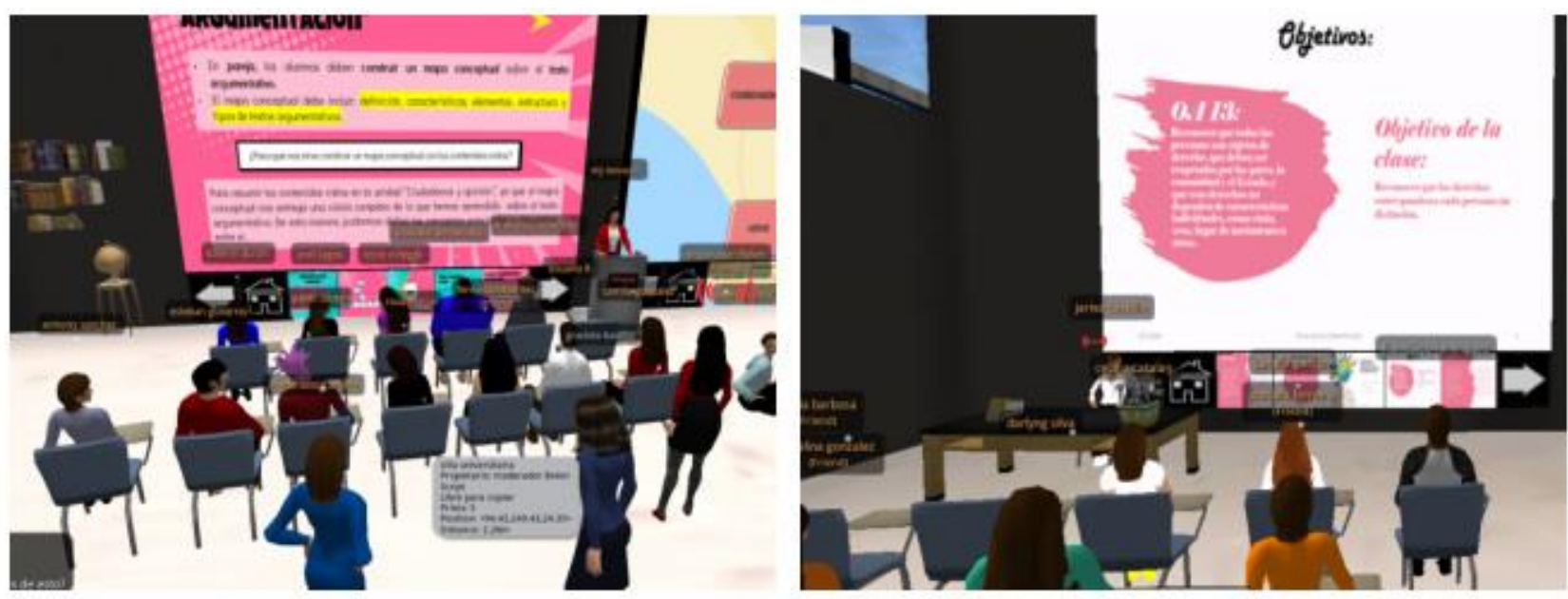

Figure 2. Scenes from activities developed in sessions. (Source: authors' own creation).

\subsection{Data Collection}

In this study, the immersive technology TINMER questionnaire was used to measure the components of the experience in the VW [25]. The validated instrument was composed of 16 items that tributed to three dimensions: (a) Interactivity (6 items); (b) Sense of presence (5 items); and (c) Flow state (5 items). The instrument was elaborated under rigorous design and validation criteria, such as a theoretical review, content analysis, a cognitive interview, a pilot test, and exploratory and confirmatory factor analyses. These also presented an adequate level of reliability, according to the ordinal alpha (0.85).

The instrument was remotely applied at the end of the educational intervention through a Google Form. For each item, participants were invited to complete the statement, "Using technology I was able to", on a Likert-type scale with 7 response options, where 1 means Very strongly disagree; 2 means Strongly disagree; 3 means Disagree; 4 means Neither agree nor disagree; 5 means Agree; 6 means Strongly agree; and 7 means Very strongly agree. The TINMER questionnaire consists of 3 dimensions and 16 items, as follow: Dimension 1. Interactivity: (1) Move virtual objects; (2) Rotate virtual objects; (3) View virtual objects from different perspectives; (4) Access information through virtual objects; (5) Move virtual objects away; and (6) Zoom in on virtual objects. Dimension 2. Presence: (7) Feel the virtual objects around me; (8) Believe that virtual objects exist in reality; (9) Feel that I was experiencing something real; (10) Feel like I was physically inside the virtual environment; and (11) Have the feeling of being in the middle of the action instead of just watching. Dimension 3: (12) Feel like the experience was enjoyable; (13) Be focused; (14) Have a sense of how well I was doing; (15) Feel like I was able to meet the challenge; and (16) Feel like time went by without noticing.

The instrument scores are calculated by adding the values obtained for each item, according to the dimension to which they belonged. Then, the resulting average was graded on the scale, using the formula TS/NI, where TS is the score obtained, and NI is the number of statements. The score was analyzed on a continuum from 1 to 7 , according to the response options.

\subsection{Data Analytics}

First, the Kolmogorov-Smirnov test was conducted to verify the assumption of normality, in which the $p$-value associated with the contrast statistic turned out to be less than 0.05 for all the variables analyzed. In effect, the data do not come from a normal distribution, so the nonparametric statistic was applied. Second, the level of agreement per dimension was assessed following the nature of the instrument's additive scale, and frequency tables were generated in order to indicate the number of observations in the response options per item. Third, Spearman's correlation was used given the ordinal nature of the variables and the non-normal distribution of the data [35]. Fourth, the Mann- 
Whitney $\mathrm{U}$ test was used to determine differences by independent groups. Descriptive and inferential analyses were run in IBM SPSS Statistics version 25 software. To calculate the effect size, $G^{*}$ Power software was used.

\section{Results}

The results for each research question are presented below.

Q1: How do preservice teachers experience their involvement in a Virtual World?

Table 2 reports the scores per dimension from the questionnaire. Upon analyzing the results in the continuum from 1 to 7 , all the variables, interactivity, presence, and flow, obtained a value of 6, corresponding to the category Strongly agree.

Table 2. Scores by dimension.

\begin{tabular}{cccccc}
\hline Dimension & Minimum Score & Maximum Score & Total Score & Number of Items & Degree of Agreement \\
\hline Interactivity & 6 & 42 & 34.42 & 6 & 6 \\
Presence & 5 & 35 & 29.67 & 5 & 6 \\
Flow & 5 & 35 & 31.59 & 5 & 6 \\
Total & 16 & 112 & 95.68 & 16 & 6 \\
\hline
\end{tabular}

Source: authors' own creation.

Table 3 refers to the frequencies reached by each item in the interactivity dimension. It can be observed that $83 \%$ of the students Very strongly agree and Strongly agree that they were able to observe objects from different perspectives (Item 3, $n=86$ ), followed by $83 \%$ of students who were able to access information through the objects (Item $4, n=85$ ). A total of $69 \%$ of the preservice teachers indicated that they Strongly agree and Very strongly agree that they were able to zoom out to virtual objects (Item $6, n=71$ ).

Table 3. Frequencies per item in the interactivity dimension.

\begin{tabular}{lcccccc}
\hline Response Categories & Item $\mathbf{1}$ & Item $\mathbf{2}$ & Item $\mathbf{3}$ & Item $\mathbf{4}$ & Item $\mathbf{5}$ & Item $\mathbf{6}$ \\
\hline & $f$ & $f$ & $f$ & $f$ & $f$ & $f$ \\
\hline Very strongly disagree & 6 & 7 & 1 & 1 & 4 & 3 \\
Strongly disagree & 2 & 3 & 0 & 0 & 1 & 1 \\
Disagree & 7 & 9 & 0 & 2 & 4 & 4 \\
Neither agree nor disagree & 12 & 21 & 3 & 5 & 11 & 7 \\
Agree & 20 & 17 & 13 & 10 & 26 & 17 \\
Strongly agree & 17 & 21 & 18 & 21 & 25 & 25 \\
Very strongly agree & 39 & 25 & 68 & 64 & 32 & 46 \\
\hline
\end{tabular}

Source: authors' own creation.

Regarding the presence dimension, it is possible to observe, in Table 4 , that $84 \%$ of the students Very strongly agree $(n=64)$ and Strongly agree $(n=23)$ that they were able to have the feeling of being in the middle of the action instead of just observing (Item 11). A total of $72 \%$ Very strongly agree $(n=50)$ and Strongly agree $(n=25)$ that they could feel that they experienced something real (Item 9), and 70\% Very strongly agree $(n=46)$ and Strongly agree $(n=26)$ that they could feel that they were physically in the VW (Item 10).

In reference to the flow dimension, $88 \%$ of students Very strongly agree $(n=58)$ and Strongly agree $(n=33)$ that they could feel that they were able to overcome the proposed challenges (Item 15); followed by $87 \%$ of students who Very strongly agreed $(n=73)$ that they could feel that the experience was enjoyable (Item 12), and 85\% Strongly agreed ( $n=75)$ that they lost track of time inside the VW (Item 16, $n=88$ ) (see Table 5).

Q2: What is the correlation between the components of experience, interactivity, sense of presence, and flow state?

Concerning the association of variables, Spearman's correlation coefficient suggests statistically significant and positive correlations. The highest relationship is observed between the dimension's presence and flow $\left(r_{s}=0.58 ; p<0.001 ; 1-\beta=0.99\right)$, followed by 
the relationship between interactivity and presence $\left(r_{s}=0.48 ; p<0.001 ; 1-\beta=0.99\right)$, and the relationship between interactivity and flow $\left(r_{S}=0.44 ; p<0.001 ; 1-\beta=0.99\right)$.

Table 4. Frequencies per item in the presence dimension.

\begin{tabular}{lccccc}
\hline Response Categories & Item 7 & Item 8 & Item $\mathbf{9}$ & Item 10 & Item 11 \\
\hline Very strongly disagree & $f$ & $f$ & $f$ & $f$ & $f$ \\
Strongly disagree & 1 & 4 & 2 & 2 & 1 \\
Disagree & 0 & 3 & 0 & 0 & 1 \\
Neither agree nor disagree & 1 & 5 & 4 & 4 & 0 \\
Agree & 27 & 14 & 1 & 7 & 6 \\
Strongly agree & 24 & 23 & 21 & 18 & 8 \\
Very strongly agree & 42 & 36 & 50 & 46 & 23 \\
Source: authors' own creation. & & & & & 64
\end{tabular}

Source: authors' own creation.

Table 5. Frequencies per item in the flow dimension.

\begin{tabular}{lccccc}
\hline Response Categories & Item 12 & Item 13 & Item 14 & Item 15 & Item 16 \\
\hline Very strongly disagree & $f$ & $f$ & $f$ & $f$ & $f$ \\
Strongly disagree & 1 & 1 & 0 & 1 & 1 \\
Disagree & 0 & 0 & 1 & 0 & 0 \\
Neither agree nor disagree & 1 & 1 & 1 & 0 & 1 \\
Agree & 4 & 3 & 9 & 1 & 5 \\
Strongly agree & 17 & 16 & 19 & 10 & 8 \\
Very strongly agree & 73 & 52 & 46 & 33 & 13 \\
\hline
\end{tabular}
Source: authors' own creation.

Q3: Are there gender differences in the components of the immersive experience?

To find out if there were significant differences in the variables' interactivity, sense of presence, and flow state, depending on gender, the nonparametric Mann-Whitney $\mathrm{U}$ test was used. The data show that there are no meaningful differences between men and women regarding interactivity and presence (see Table 6). On the contrary, there are gender differences in the flow variable, where women experience a greater sense of concentration and enjoyment compared to men. The effect size $(1-\beta=0.43)$ indicates that this difference is moderate [36].

Table 6. Gender differences in components of the immersive experience.

\begin{tabular}{|c|c|c|c|c|c|c|c|}
\hline \multirow{3}{*}{ Variables } & \multicolumn{2}{|c|}{ Gender } & \multirow{3}{*}{$\mathbf{Z}$} & \multirow{3}{*}{$\mathbf{U}$} & \multirow{3}{*}{$p$} & \multirow{3}{*}{$1-\beta$} & \multirow{3}{*}{$d$} \\
\hline & $\begin{array}{c}\text { Boys } \\
n=22\end{array}$ & $\begin{array}{c}\text { Girls } \\
n=81\end{array}$ & & & & & \\
\hline & Average Range & Average Range & & & & & \\
\hline Interactivity & 45.02 & 53.90 & -1.23 & 737 & 0.21 & & \\
\hline Presence & 43.86 & 54.21 & -1.45 & 712 & 0.14 & & \\
\hline Flow & 40.64 & 55.09 & -2.03 & 641 & $0.04^{*}$ & 0.43 & 0.47 \\
\hline
\end{tabular}

\section{Discussion}

The results of the analysis largely support the proposed research hypotheses.

Firstly, students reported a very favorable level of agreement with the immersive experience (H1). The results are consistent with previous analyses. In a study by Chen and $\mathrm{Hsu}$, it was found that students lost track of time when using immersive technology, believed that the environment was real, and felt calmness and enjoyment [37]. On the other hand, in Kwon's study, most of the participants were able to touch and manipulate virtual objects and observe them as if they were physically on-site [27]. According to the literature, the use of the Virtual World allows for real-time mental states to occur in the 
learner. The interactivity facilitates the representation of knowledge, the sense of presence allows navigation and exploration in a context that turns out to be realistic, and the state of flow enhances concentration on the stimuli provided. Consequently, greater learning gains are obtained when the learner experiences them $[18,23,25]$.

Secondly, a modest and positive association between interactivity and sense of presence (H2) was found. This finding is consistent with previous empirical studies $[23,27,38,39]$. Recently, Sandoval-Henríquez and Badilla-Quintana reported a substantial and moderate association $(r=0.46 ; p<0.001)$ following an intervention with immersive technology for teaching natural science content [25]. In contrast to these findings, Mütterlein and Munich ran a structural equation modeling analysis and reported a low and significant correlation between both constructs $(\beta=0.24, p<0.001)$ following intervention with the VW technology conducted in a shopping mall to inquire about purchase intention. However, the authors attribute this low correlation to the design of the technology intervention [40]. In this sense, virtual environments require a dynamic simulation that allows the student to move through the different environments, manipulate virtual objects, and interact with others.

Thirdly, a moderate and positive correlation was obtained between interactivity and flow state (H3). This result is concordant with previous studies [21,25,30,31,38,41]. Specifically, Choi and Baek showed that interactivity and flow possess a significant and positive correlation $(r=0.70 ; p<0.001)$. In addition, the authors argue that, when designing instruction in a Virtual World, interactivity characteristics should be considered because when students effectively recognize this property, the level of flow increases [42]. Complementarily, Rodríguez-Ardura and Meseguer-Artola mention that environments that are considered to be interactive are more likely to be perceived as engaging and enjoyable [19].

Fourthly, a moderate and positive association was found between a sense of presence and flow state (H4). This finding is consistent with previous research, e.g., $[19,32,38,43]$. Recently, Choi and Noh conducted a structural equation modeling analysis where a positive and significant association was found between both constructs $(\beta=0.56, p<0.001)$. The authors inferred that students who experienced a higher level of presence while watching handwashing promotion content with immersive technology were more likely to experience flow [32]. There is broad consensus in the literature that the sense of presence and flow state are correlated, although they are considered as different constructs and subjective experiences [19].

Fifthly, we hypothesized significant differences between the VW components in favor of men (H5), given their frequent use of videogames and greater experience. It was found that there were no differences by gender in the interactivity and sense of presence components. Therefore, the findings obtained turned out to be consistent with the study by Warden et al., which concludes that gender does not influence immersive experiences in a VW. The authors postulate that teachers could implement these learning environments with confidence and without concerns [33].

Regarding flow state, significant differences were found in favor of females. These results vary from previous ones claiming no gender differences [33,44,45]. Specifically, Huang and Tsau presented an artwork with immersive technology. Their results indicate that users can interact through their senses and briefly escape from the real world as if they were immersed in an illusion, and they show that there is no significant difference in the degree of flow experience between genders, arguing that the artwork with technology can facilitate promotion between both viewers [44].

\section{Conclusions}

On the basis of the previously shared theoretical elements and empirical data, it is possible to affirm that virtual worlds could contribute to the strengthening of preservice teachers' pedagogical skills, among other advantages, and that students could react positively to such practices. In other words, the effectiveness of preservice teachers' education curriculum acquisition may increase when students can simulate teaching scenarios. In 
this context, abstract concepts become more concrete and practicable, narrowing the gaps between theory and practice.

First, prior studies have used different terms to refer to this technology. For example, the literature refers to it as multiuser virtual environments (MUVEs), 3D immersive virtual environments, the immersive virtual world (IVW), the virtual learning environment (VLE), among others. This proliferation of seemingly innocuous terms detracts from their analytical value and limits the progress of its study in the educational field. Therefore, the framework proposed by Girvan, which delivers technical characteristics and components of the experience of a VW, was used to carry out this study [9]. In this sense, we hope to contribute to the clarity of the concept, providing starting points for researchers and teachers who wish to incorporate this technological resource into the classroom.

Second, as for the VW technical characteristics, an environment that simulated a university campus was designed on the OpenSim platform. This software allowed for the creation of avatars, where each student, through their digital representation, interacted with a vision in both the first and third person. The VW could support several users connected through the local network. Participants came from diverse geographical locations, including three different countries. Communication within the VW was facilitated by the tools incorporated in OpenSim, such as text and voice chat, which allow public and private messaging systems. These were essential for the dynamics of each session. The platform allowed for loading content into external software packages. For example, Blender was used to load virtual objects from the educational context, panels, chairs, tables, computers, among others. The OpenSim software also made it possible to store the objects created by the students, helping them demonstrate the VW's persistence and interaction characteristics. There are currently other platforms in operation, such as SecondLife, Decentraland, Active Worlds, There, and Minecraft. Future research could compare and analyze whether these systems fit into the educational sphere, and whether they mostly contribute to the VW technical characteristics. For example, while OpenSim allows objects to be loaded from other external software, some platforms facilitate content generation while still being in the VW.

Third, as for the experience components, students were able to interact in the VW, and this was reflected in the actions they performed, such as, among others, changing slides in the different panels to visualize learning content; placing their avatar on chairs and podiums; creating costumes and changing the default appearance of their avatar; adding their classmates to the friends list and establishing a conversation by chat or phone call; manipulating and observing objects in the VW; and teleporting to different locations in the VW. At the same time, they were able to experience a sense of presence, i.e., the feeling of being present in the simulated environment. While participants expressed a favorable level of agreement with this dimension, different results may be found in future research, where students categorically report not experiencing a sense of presence. However, it is difficult for students not to perceive being co-present in a space with multiple users and with numerous opportunities for communication. Future research should specify the construct to be measured, since it is vast. We have approached presence from a generic conception, according to the applied instrument, but it is possible to address it from different typologies (for example, social presence, physical presence, and self-presence). For more information, we recommend Lee [46]. The students were also able to experience a state of flow, i.e., the feeling that the experience was pleasant, that time passed without notice, and that they overcame the proposed challenges. Given the findings, it is possible to accept Hypothesis 1, that students report a positive level of agreement with the immersive experience.

Hypotheses 2-4 are also accepted since there are positive and significant correlations between the VW components: interactivity, sense of presence, and flow state. Literature on immersive technologies, such as augmented reality and virtual reality, has shown that this association leads to better learning. Previous research reports the positive effects of VW integration on variables, such as academic performance and academic engagement, which is complex, as the students' mental reactions when using these environments have not 
been explored. In this sense, future research should develop a structural equation model to analyze the effects of cognitive reactions on learning.

Hypothesis 5 was rejected. Significant differences were found in the VW components in favor of men and, in our understanding, this is given the frequent use of computers and videogames. Differences were only found in the flow state in favor of women. Our results can be explained statistically and theoretically. An equal sample distribution between men and women is required, as the effect size for this difference is moderate. Women represented $79 \%$ of the sample, and this could generate some comfort and security in participating in the study. Within the Virtual World setting, women tend to avoid communicating with male users, and even when they are on par with men, they feel less secure. Research has made progress in this area, and there is interest in how avatar embodiment can either diminish stud insecurities or affect immersive experiences [47]. Future research may explore how male and female students conceive their identities through avatars.

Fourth, the educational intervention within the VW was designed based on the Experiential Learning Theory, which establishes four modes of learning [26]. The intervention sought to strengthen the pedagogical and technological skills of preservice teachers, in which the participants had to design and execute educational activities assuming the teacher role. This study contributes to a deeper understanding of how activities in the VW could be designed to enable each mode of experiential learning: concrete experience, reflective observation, abstract conceptualization, and active experimentation.

Finally, it is possible to suggest the curricular integration of immersive technology as a sustainable technological resource that contributes specific employability skills that the students should develop for their future practice. Moreover, immersive technologies also enable initial teacher trainers to navigate through complex curricular areas and the acquisition of content knowledge, such as science education in terms of assessment, curriculum, and disciplinary content. Typically, experiential learning activities in higher education are taking place in the real world. However, the COVID-19 health emergency has affected the regular course of these activities in face-to-face mode. Students in initial teacher training have not entered into pedagogical practice spaces, understanding that these allow them to observe, experience, and analyze the educational process, as well as to establish asynchronous and direct interaction with the educational communities. Given this, experiential learning activities through the VW allow the fulfillment of established academic objectives and provide continuity to learning. Thus, this research constitutes an initiative for the simulation of pedagogical practices for preservice teachers.

The virtual world distinguishes itself from other types of technologies by replicating a hypothetical simulation of real life in a dynamic and graphically enriched environment, enabling the development of pedagogical and technological competences for sustainable learning in the real world. As our study indicates, immersive technology, such as 3D environments, are a sustainable technology that can help initial teacher trainers to practice teaching in the same way as students who are practicing face-to-face in schools. We propose that the incorporation of these kinds of environments could be a fruitful area for further work since the immersive and embodied experience could create scenarios in which initial teacher trainers can improve their teaching performance, as well as their confidence and disciplinary knowledge.

\section{Implications}

The results obtained have a series of implications. In theoretical terms, this study extends the state of the literature on immersive technology in education, particularly the Virtual World as a support for the simulation of the pedagogical practices of students in initial teacher training (ITT). In addition, the intervention, developed within the COVID-19 pandemic context, is detailed. This may serve as an orientation for the scientific community in future research, thereby discovering new potential for this technology.

In practical terms, this study describes the simulation of pedagogical practices through different activities or challenges that are linked to the school context. Initial teacher training 
has been affected by the spread of the virus and schools have adopted a remote mode of teaching to ensure the welfare of their communities. Educational organizations and academics can incorporate this technology in their training itineraries to promote direct contact and the presence of ITT students within the school system.

Author Contributions: M.G.B.-Q. designed the project, oversaw the study, analyzed the results, and wrote the manuscript. F.J.S.-H. acted as educational expert, participated in the experiment, and wrote the manuscript. All authors have read and agreed to the published version of the manuscript.

Funding: This study is based upon work supported by the National Agency for Research and Development, ANID, Chile, under Grant Number 1191891, awarded to María Graciela Badilla-Quintana, (PI) Regular Fondecyt Project, "Integration of immersive technologies in education. Learning mechanisms and educational practices from teacher training". Any opinions, findings, conclusions, or recommendations expressed in this material are those of the author(s) and do not necessarily reflect the views of ANID.

Institutional Review Board Statement: This study was approved by the Ethics, Bioethics and Biosafety Committee of the Universidad Católica de la Santísima Concepción. Approval Code: VRIP14. Approval Date: 20 June 2019.

Informed Consent Statement: Informed consent was signed by all the participants in the study.

Data Availability Statement: The data presented in this study is available upon request to the corresponding author.

Conflicts of Interest: The authors declare no conflict of interest.

\section{References}

1. OECD. The State of School Education: One Year into the COVID Pandemic; OECD: Paris, France, 2021.

2. Corell-Almuzara, A.; López-Belmonte, J.; Marín-Marín, J.-A.; Moreno-Guerrero, A.-J. COVID-19 in the Field of Education: State of the Art. Sustainability 2021, 13, 5452. [CrossRef]

3. Ghanbarzadeh, R.; Ghapanchi, A.H. Uncovering educational outcomes deriving from students' acceptance and involvement with 3D virtual worlds. Educ. Inf. Technol. 2021, 26, 311-337. [CrossRef]

4. Lorenzo-Alvarez, R.; Pavia-Molina, J.; Sendra-Portero, F. Exploring the Potential of Undergraduate Radiology Education in the Virtual World Second Life with First-cycle and Second-cycle Medical Students. Acad. Radiol. 2018, 25, 1087-1096. [CrossRef] [PubMed]

5. Díaz, J.E.M. Virtual World as a Complement to Hybrid and Mobile Learning. Int. J. Emerg. Technol. Learn. (iJET) 2020, 15, 267-274. [CrossRef]

6. Seifan, M.; Robertson, N.; Berenjian, A. Use of virtual learning to increase key laboratory skills and essential non-cognitive characteristics. Educ. Chem. Eng. 2020, 33, 66-75. [CrossRef]

7. Winkelmann, K.; Keeney-Kennicutt, W.; Fowler, D.; Macik, M. Development, Implementation, and Assessment of General Chemistry Lab Experiments Performed in the Virtual World of Second Life. J. Chem. Educ. 2017, 94, 849-858. [CrossRef]

8. Winkelmann, K.; Keeney-Kennicutt, W.; Fowler, D.; Macik, M.L.; Guarda, P.P.; Ahlborn, C.J. Learning gains and attitudes of students performing chemistry experiments in an immersive virtual world. Interact. Learn. Environ. 2020, 28, 620-634. [CrossRef]

9. Girvan, C. What is a virtual world? Definition and classification. Educ. Technol. Res. Dev. 2018, 66, 1087-1100. [CrossRef]

10. Kawulich, B.B.; D'Alba, A. Teaching qualitative research methods with Second Life, a 3-dimensional online virtual environment. Virtual Real. 2019, 23, 375-384. [CrossRef]

11. Lorenzo-Alvarez, R.; Rudolphi-Solero, T.; Ruiz-Gómez, M.J.; Sendra-Portero, F. Game-Based Learning in Virtual Worlds: A Multiuser Online Game for Medical Undergraduate Radiology Education within Second Life. Anat. Sci. Educ. 2019, 13, 602-617. [CrossRef]

12. Quintana, M.G.B.; Meza-Fernández, S. A pedagogical model to develop teaching skills. The collaborative learning experience in the Immersive Virtual World TYMMI. Comput. Hum. Behav. 2015, 51, 594-603. [CrossRef]

13. Linganisa, A.; Ako-Nai, A.; Ajayi, N. The Potential of Second Life as a Platform for Learning: Student's Perspective. In Proceedings of the 2018 International Conference on Intelligent and Innovative Computing Applications (ICONIC), Pointe aux Biches, Mauritius, 6-7 December 2018; pp. 1-5.

14. Pereira, M.M.; Artemiou, E.; Mcgonigle, D.; Conan, A.; Sithole, F.; Jean, K.Y.-S. Using the Virtual World of Second Life in Veterinary Medicine: Student and Faculty Perceptions. J. Vet. Med. Educ. 2018, 45, 148-155. [CrossRef] [PubMed]

15. Shonfeld, M.; Greenstein, Y. Factors promoting the use of virtual worlds in educational settings. Br. J. Educ. Technol. 2021, 52, 214-234. [CrossRef]

16. Thorne, M.; MacGregor, C. Pedagogy and Learning for Sustainability in a Virtual World Scaffold; Springer: Singapore, 2017; pp. 9-23. 
17. Abad-Segura, E.; González-Zamar, M.-D.; Rosa, A.L.-D.L.L.-D.L.; Cevallos, M.B.M. Sustainability of Educational Technologies: An Approach to Augmented Reality Research. Sustainability 2020, 12, 4091. [CrossRef]

18. Gomez, L.I. Immersive Virtual Reality for Learning Experiences. In Applied Degree Education and the Future of Work; Springer: Berlin/Heidelberg, Germany, 2020; pp. 183-198.

19. Rodríguez-Ardura, I.; Meseguer-Artola, A. Chapter 12 Immersive Experiences in Online Higher Education: Virtual Presence and Flow. In The Future of Innovation and Technology in Education: Policies and Practices for Teaching and Learning Excellence; Emerald Publishing Limited: Bingey, UK, 2018; pp. 187-202.

20. Steuer, J. Defining Virtual Reality: Dimensions Determining Telepresence. J. Commun. 1992, 42, 73-93. [CrossRef]

21. Lee, W.-J.; Kim, Y. Does VR Tourism Enhance Users' Experience? Sustainability 2021, 13, 806. [CrossRef]

22. Slater, M. Place illusion and plausibility can lead to realistic behaviour in immersive virtual environments. Philos. Trans. R. Soc. $B$ Biol. Sci. 2009, 364, 3549-3557. [CrossRef] [PubMed]

23. Selzer, M.N.; Gazcon, N.F.; Larrea, M.L. Effects of virtual presence and learning outcome using low-end virtual reality systems. Displays 2019, 59, 9-15. [CrossRef]

24. Csikszentmihalyi, M. Flow: The Psychology of Optimal Experience; Harper \& Row: New York, NY, USA, 1990.

25. Sandoval-Henríquez, F.J.; Badilla-Quintana, M.G. Measuring stimulation and cognitive reactions in middle schoolers after using immersive technology: Design and validation of the TINMER questionnaire. Comput. Educ. 2021, 166, 104157. [CrossRef]

26. Kolb, D. Experiential Learning: Experience As The Source Of Learning And Development; Prentice Hall: Englewood Cliffs, NJ, USA, 1984.

27. Kwon, C. Verification of the possibility and effectiveness of experiential learning using HMD-based immersive VR technologies. Virtual Real. 2018, 23, 101-118. [CrossRef]

28. Su, W.; Han, X.; Yu, H.; Wu, Y.; Potenza, M.N. Do men become addicted to internet gaming and women to social media? A meta-analysis examining gender-related differences in specific internet addiction. Comput. Hum. Behav. 2020, 113, 106480. [CrossRef]

29. Dewey, J. Experience E Education; Kappa Delta Pi: New York, NY, USA, 1938.

30. Barker, V.E. Flow in Virtual Worlds: The Interplay of Community and Site Features as Predictors of Involvement. J. Virtual Worlds Res. 2016, 9, 1-19. [CrossRef]

31. Novak, T.P.; Hoffman, D.L.; Yung, Y.-F. Measuring the Customer Experience in Online Environments: A Structural Modeling Approach. Mark. Sci. 2000, 19, 22-42. [CrossRef]

32. Choi, D.-H.; Noh, G.-Y. The effect of presence in virtual reality video on handwashing intention. Asian J. Commun. 2020, 30, 261-278. [CrossRef]

33. Warden, C.A.; Stanworth, J.O.; Chang, C.-C. Leveling up: Are non-gamers and women disadvantaged in a virtual world classroom? Comput. Hum. Behav. 2016, 65, 210-219. [CrossRef]

34. Creswell, J.W.; Creswell, J.D. Research Design: Qualitative, Quantitative, and Mixed Methods Approaches; SAGE Publications: Thousand Oaks, CA, USA, 2017.

35. Field, A. Discovering Statistics Using IBM SPSS Statistics; Sage Publishing: Thousand Oaks, CA, USA, 2017.

36. Castro, J.M.C. Potencia estadística y cálculo del tamaño del efecto en G*Power: Complementos a las pruebas de significación estadística y su aplicación en psicología. Salud Soc. 2014, 5, 210-244. [CrossRef]

37. Chen, Y.-L.; Hsu, C.-C. Self-regulated mobile game-based English learning in a virtual reality environment. Comput. Educ. 2020, 154, 103910. [CrossRef]

38. Cheng, L.-K.; Chieng, M.-H.; Chieng, W.-H. Measuring virtual experience in a three-dimensional virtual reality interactive simulator environment: A structural equation modeling approach. Virtual Real. 2014, 18, 173-188. [CrossRef]

39. Huang, C.; Liao, J.; Lin, T.; Hsu, H.; Lee, T.C.; Guo, J. Effects of user experiences on continuance intention of using immersive three-dimensional virtual reality among institutionalized older adults. J. Adv. Nurs. 2021, 77, 3784-3796. [CrossRef]

40. Mütterlein, J.; Munich, L.M.U. The Three Pillars of Virtual Reality? Investigating the Roles of Immersion, Presence, and Interactivity. In Proceedings of the 51st Hawaii International Conference on System Sciences, Waikoloa Village, HI, USA, 3-6 January 2018. Available online: http:/ / hdl.handle.net/10125/50061 (accessed on 12 November 2021).

41. Arghashi, V.; Yuksel, C.A. Interactivity, Inspiration, and Perceived Usefulness! How retailers' AR-apps improve consumer engagement through flow. J. Retail. Consum. Serv. 2022, 64, 102756. [CrossRef]

42. Choi, B.; Baek, Y. Exploring factors of media characteristic influencing flow in learning through virtual worlds. Comput. Educ. 2011, 57, 2382-2394. [CrossRef]

43. Rodriguez-Ardura, I.; Meseguer-Artola, A. What leads people to keep on e-learning? An empirical analysis of users' experiences and their effects on continuance intention. Interact. Learn. Environ. 2014, 24, 1030-1053. [CrossRef]

44. Huang, M.-H.; Tsau, S.-Y. A Flow Experience Analysis on the Virtual Reality Artwork. In Proceedings of the International Conference on Machine Vision and Applications_ICMVA 2018; ACM Press: New York, NY, USA, 2018; pp. 51-55.

45. Plummer, J.P.; Schuster, D.; Keebler, J. The effects of gender, flow and video game experience on combat identification training. Ergon. 2017, 60, 1101-1111. [CrossRef] [PubMed]

46. Lee, K.M. Presence explicated. Commun. Theory 2004, 14, 27-50. [CrossRef]

47. Martens, A.L.; Grover, C.A.; Saucier, D.A.; Morrison, B.A. An examination of gender differences versus similarities in a virtual world. Comput. Hum. Behav. 2018, 84, 404-409. [CrossRef] 